\title{
Nonsteroid Anti-Inflammatory Drugs Inhibit Both the Activity and the Inflammation-Induced Expression of Acid-Sensing lon Channels in Nociceptors
}

\author{
Nicolas Voilley, Jan de Weille, Julien Mamet, and Michel Lazdunski \\ Institut de Pharmacologie Moléculaire et Cellulaire, Centre National de la Recherche Scientifique Unité, Mixte de \\ Recherche 6097, Sophia Antipolis, 06560 Valbonne, France
}

Nonsteroid anti-inflammatory drugs (NSAIDs) are major drugs against inflammation and pain. They are well known inhibitors of cyclooxygenases (COXs). However, many studies indicate that they may also act on other targets. Acidosis is observed in inflammatory conditions such as chronic joint inflammation, in tumors and after ischemia, and greatly contributes to pain and hyperalgesia. Administration of NSAIDs reduces low-pHinduced pain. The acid sensitivity of nociceptors is associated with activation of $\mathrm{H}^{+}$-gated ion channels. Several of these, cloned recently, correspond to the acid-sensing ion channels (ASICs) and others to the vanilloid receptor family. This paper shows (1) that ASIC mRNAs are present in many small sensory neurons along with substance $P$ and isolectin $B 4$ and that, in case of inflammation, ASIC1a appears in some larger $A \beta$ fibers, (2) that NSAIDs prevent the large increase of ASIC expression in sensory neurons induced by inflammation, and (3) that NSAIDs such as aspirin, diclofenac, and flurbiprofen directly inhibit ASIC currents on sensory neurons and when cloned ASICs are heterologously expressed. These results suggest that the combined capacity to block COXs and inhibit both inflammationinduced expression and activity of ASICs present in nociceptors is an important factor in the action of NSAIDs against pain.

Key words: acid-sensing ion channel; inflammation; dorsal root ganglion; nociception; aspirin; NSAID
Nonsteroid anti-inflammatory drugs (NSAIDs) have been generally considered as inhibitors of cyclooxygenases (COXs) (Walker, 1995; Vane and Botting, 1998). Their anti-inflammatory and analgesic action is thought to be mainly mediated via this inhibition. However, data have been accumulating through the years suggesting that NSAIDs also probably act on other targets to counteract pain. One recent result in this regard is that COX-1and COX-2-deficient mice still show sensitivity to the analgesic action of NSAIDs (Ballou et al., 2000). On the other hand, administration of NSAIDs reduces both cutaneous (Steen et al., 1996) and corneal (Chen et al., 1997) pain induced by exposure to acidic $\mathrm{pH}$ in the absence of inflammation.

Tissue acidosis is a dominant factor in inflammation and in tumors and after ischemia (Reeh and Steen, 1996; Helmlinger et al., 1997) and has an important contribution in pain and hyperalgesia (Steen and Reeh, 1993; Steen et al., 1995). This is attributable to direct excitation of nociceptive sensory neurons by $\mathrm{H}^{+}$-gated currents (Krishtal and Pidoplichko, 1981a; Bevan and Yeats, 1991). Several channels corresponding to these currents have been cloned recently and belong to the acid-sensing ion channel (ASIC) family (Waldmann et al., 1996, 1997a,b; Lingueglia et al., 1997; Chen et al., 1998) and to the vanilloid receptor family (Caterina et al., 1997; Tominaga et al., 1998) (for review, see Kress and Zeilhofer, 1999). Different ASIC isoforms have

\footnotetext{
Received June 11, 2001; revised July 20, 2001; accepted July 26, 2001.

This work was supported by the Centre National de la Recherche Scientifique, the Association Française contre les Myopathies, and the Association pour la Recherche sur le Cancer. We thank Dr. F. Kuper and Dr. A. Baron for fruitful discussion and M. Jodar and C. Widmann for expert technical assistance.

Correspondence should be addressed to Prof. Michel Lazdunski, Institut de Pharmacologie Moléculaire et Cellulaire, Centre National de la Recherche Scientifique Unité Mixte de Recherche 6097, 660 route des Lucioles, Sophia Antipolis, 06560 Valbonne, France. E-mail: ipmc@ipmc.cnrs.fr.

Copyright (ㄷ) 2001 Society for Neuroscience $0270-6474 / 01 / 218026-08 \$ 15.00 / 0$
}

been identified and characterized: ASIC1a (Waldmann et al., 1997a) and its splice variant ASIC1b (Chen et al., 1998), both present in dorsal root ganglion (DRG) neurons; ASIC2a (Waldmann et al., 1996) and ASIC2b (Lingueglia et al., 1997), the latter being the more abundant in DRGs and the former being only present in large DRG neurons (Garcia-Añoveros et al., 2001); and ASIC3 (Waldmann et al., 1997b), abundant in peripheral sensory neurons and thought to mediate cardiac ischemic pain (Sutherland et al., 2001). This paper examines the relationships between ASICs, nociceptors, and inflammatory pain and shows that NSAIDs inhibit the activity of this class of channels in a COX-independent way, as well as their inflammation-induced expression.

\section{MATERIALS AND METHODS}

In situ hybridization. Sections (12 $\mu \mathrm{m}$ thick) of L4-L5 DRGs from normal or inflamed adult rats were fixed and hybridized $\left(15 \mathrm{hr}\right.$ at $\left.52^{\circ} \mathrm{C}\right)$ in $12.5 \%$ formamide, $4 \times$ SSC, $2.5 \times$ Denhardt's solution, $250 \mu \mathrm{g} / \mathrm{ml}$ herring sperm DNA, $125 \mu \mathrm{g} / \mathrm{ml}$ yeast tRNA, and $5 \mathrm{ng} / \mu$ l oligonucleotides labeled with biotin-21-dUTP by terminal transferase. For fluorescent labeling, detection was performed with the ELF-97 mRNA In situ Hybridization kit (Molecular Probes, Eugene, OR) based on streptavidin-alkaline phosphatase-biotinylated probe interaction and the substrate ELF-97, which yields green fluorescent precipitates. For diaminobenzidine labeling, detection was performed with Dako (High Wycombe, UK) GenPoint with two cycles of amplification. Counterstain used hematoxylin. Probes were as follows: ASIC1a, CATTCTTGGAGACTTGGCTAAAGCGGAAC; ASIC1b, GGGTCATCACTCTCATCCAGTCCTAGCAT; ASIC2b, CCCAAACGGTCCATGAAGGCAGC; and ASIC3, CTGTTCCAGAAATACCCCAGGAC. Results were confirmed with a second set of probes. Control experiments were performed with ASIC1a sense oligonucleotide (CACAGATGGCTGATGAAAAGCAG), and background was assessed without probe. Each experiment was done on at least three animals.

Substance P immunochemistry and isolectin B4 binding. After in situ hybridization, slides were treated with anti-substance P (SP) antibody (dilution of 1:100; Sigma, St. Louis, MO) and revealed with anti-IgG 
Texas Red-coupled antibodies (Jackson ImmunoResearch, West Grove, PA). For isolectin B4 (IB4) binding, FITC-labeled IB4 was applied at $12.5 \mu \mathrm{g} / \mathrm{ml}$. IB4-positive cells appeared green, which was changed to red with Adobe PhotoShop 5.0 (Adobe Systems, San Jose, CA) before superposition with ASIC-labeled pictures. Cell proportions and profiles were calculated by measuring individually and counting cells.

Inflammation experiments. Right hindpaws of anesthetized male Wistar rats (7-9 weeks) were inflamed by a $50 \mu$ injection of complete Freund's adjuvant (Stein et al., 1988). L4-L5 DRGs were removed at day 2 on both sides, the left ganglia serving as negative controls. The anti-inflammatory drug was infused intraperitoneally when the injection of adjuvant was given and was repeated the next day. The drugs used were (in $\mathrm{mg} / \mathrm{kg}$ ): 8 diclofenac, 4 ibuprofen, 40 salicylate, 40 aspirin, 20 nimesulide, 8 nordihydroguaiaretic acid (NDGA), 0.1 dexamethasone (all from Sigma), 20 Zileuton (kindly provided by Abbott Labs, Irving, TX), or 20 MK-886 (kindly provided by Merck-Frosst, Dorval, Quebec, Canada).

Reverse transcription-PCR experiments. Total RNA $(2 \mu \mathrm{g})$ was reverse transcripted (First-strand cDNA synthesis kit; Amersham Pharmacia Biotech, Arlington Heights, IL). One-twentieth was used per PCR condition. Primers used were $\left(5^{\prime}-3^{\prime}\right.$, sense/antisense): ASIC1a (Waldmann et al., 1997a), CACAGATGGCTGATGAAAAGCAG/CATGGTAACAGCATTGCAGGTGC; ASIC1b (Chen et al., 1998), ATGCCGTGCGGTTGTCCC/same as ASIC1a; ASIC2a (Waldmann et al., 1996), TCAACCTACAGATTCCCGACCCG/CGAGTCCCATCTCTGAGGACCGG; ASIC2b (Lingueglia et al., 1997), CTGCCTTCATGGACCGTTTG/same as ASIC2a; ASIC3 (Waldmann et al., 1997b), CCCAGACCCAGACCCAGCCCTCC/CTGTTCCAGAAATACCCCAGGAC; and $\beta$-actin (Nudel et al., 1983), GTGCCCATCTATGAGGGTTACGCG/GGAACCGCTCATTGCCGATAGTG. Analysis was performed after scanning autoradiograms of dot blots and/or ethidium bromide-stained agarose gel pictures (both gave the same results) with the NIH Image program. Results were normalized with actin signals. Calcitonin gene-related peptide mRNA level measurement was systematically performed by reverse transcription (RT)-PCR to assess the efficiency of the inflammatory treatment (Donaldson et al., 1992) with the primers TCTGAAGTTCTCCCCTTTCCTGG/GAAGGGTTTCAGTACCAAGAATG (Amara et al., 1985). Specific VR1 expression was measured using AGACAGACAGCCTGAAGCAGTTT/CTTGTCACGAACTTGGTGTTGTC (Caterina et al., 1997), VRL1 expression with TGCCGCCGCTACACCTTGGCTTC/GCTCCTGCTGGCTGGGAGCAGAA (Caterina et al., 1999), and VR5'sv expression using CCTCTTGGTGGAGAATGGAGCAG/same as VR1 (Schumacher et al., 2000).

Electrophysiology. Ion currents were recorded at room temperature on ASIC3-, ASIC1a-, or ASIC2a-transfected COS cells or on DRG neuron primary cultures using whole-cell or outside-out patch clamp and analyzed with Serf freeware (www.bram.org/serf/). Cells were voltage clamped at $-60 \mathrm{mV}$. The pipette solution contained (in $\mathrm{mM}$ ): $120 \mathrm{KCl}$, $30 \mathrm{NaCl}, 2 \mathrm{MgCl}_{2}, 5$ EGTA, and 10 HEPES, pH 7.2. The bath solution contained (in mM): $140 \mathrm{NaCl}, 5 \mathrm{KCl}, 2 \mathrm{MgCl}_{2}, 2 \mathrm{CaCl}_{2}$, and $10 \mathrm{HEPES}$, $\mathrm{pH}$ 7.3. Solutions used for $\mathrm{pH}$ shifts were $\mathrm{pH} 5$ for ASIC1a-transfected COS cells, pH 4 for ASIC3-transfected cells, and a more pathophysiological $\mathrm{pH} 6$ for DRG cells, all giving comparable currents. These solutions were buffered with $10 \mathrm{mM}$ MES plus $10 \mathrm{~mm}$ glycine instead of HEPES. After transient $\mathrm{pH}$ drops, NSAID solution was preapplied extracellularly for $10 \mathrm{sec}$ before and during new $\mathrm{pH}$ changes.

Primary culture experiments. Dorsal root ganglion cells were prepared from Wistar adult male (5-7 weeks) and newborn rats by $0.1 \%$ collagenase dissociation and plating on collagen-coated P35 dishes in DMEM plus $5 \%$ fetal calf serum.

\section{RESULTS}

\section{ASIC transcripts are present in small DRG neurons, and their levels are increased by inflammation}

Using a double-labeling technique combining in situ hybridization and histochemistry, we were able to localize ASIC transcripts in small sensory neurons i.e., nociceptors (Fig. 1A). ASIC1a and ASIC3 are present in many SP- and IB4-positive neurons. SP and IB4 are specific markers of the two groups of unmyelinated nociceptors (C fibers), the neuropeptidergic fibers and the nonpeptidergic fibers, respectively (Snider and McMahon, 1998). ASIC1a is expressed in $62 \pm 9 \%$ of SP-positive and $41 \pm 4 \%$ of
IB4-positive cells. Some SP-positive $(40 \pm 8 \%)$ and IB4-positive $(48 \pm 13 \%)$ cells do not express ASIC1a. ASIC3 is expressed in $50 \pm 7 \%$ of SP-positive and $43 \pm 9 \%$ of IB4-positive cells. Some SP-positive $(48 \pm 13 \%)$ and IB4-positive $(39 \pm 15 \%)$ cells do not express ASIC3. Similar labeling patterns were observed for ASIC1b and for ASIC2b (data not shown), which are expressed in SP- and IB4-positive and -negative neurons in the same proportions as the other ASICs (i.e., 40-50\%).

In normal conditions, ASIC1a mRNA is mainly expressed in cells with cross-sectional areas between 200 and $600 \mu \mathrm{m}^{2}$ (mean area, $522 \pm 36 \mu \mathrm{m}^{2}$ ) that correspond to cell diameters between 15 and $30 \mu \mathrm{m}$ (Fig. 1B). In inflammatory conditions, this area increases significantly to $722 \pm 39 \mu \mathrm{m}^{2}(p<0.001)$. This increase can be explained by the appearance of a population of ASIC1apositive cells with areas of $600-1200 \mu \mathrm{m}^{2}$ (i.e., $30-40 \mu \mathrm{m}$ in diameter). The area of cells coexpressing the ASIC1a transcript and SP is increased from $514 \pm 47 \mu \mathrm{m}^{2}$ in normal conditions to $664 \pm 30 \mu \mathrm{m}^{2}$ in inflamed conditions $(p<0.006)$ and the number of coexpressing cells from $40 \pm 4$ to $62 \pm 7 \%(p<0.03)$. No difference in ASIC3 distribution has been observed between normal $\left(705 \pm 43 \mu \mathrm{m}^{2}\right)$ and inflammatory $\left(653 \pm 33 \mu \mathrm{m}^{2}\right)$ conditions (Fig. 1B). There is no significant difference for ASIC1b (560 \pm 28 vs $\left.556 \pm 33 \mu \mathrm{m}^{2}\right)$ and ASIC2b (677 \pm 35 vs $729 \pm 44 \mu \mathrm{m}^{2}$ ) either (data not shown).

The mRNA levels of the different ASICs mainly expressed in DRGs are highly increased 1-2 d after Freund's adjuvant-induced inflammation (Fig. 2A,B). The highest increase was found for ASIC1a, ASIC2b, and ASIC3 (from sixfold to 15-fold) by semiquantitative RT-PCR, the only feasible technique because the amount of RNA in individual DRGs is low. ASIC2a mRNA that we find either undetectable or present at a low level in control DRG cells remains at a low level after inflammation. Indeed, ASIC2a is present in large mechanosensitive neurons (GarciaAñoveros et al., 2001) that have no nociceptive role.

The transcript levels of the different vanilloid receptors were measured on the same samples. No difference was observed in VR1 transcript level between normal and inflamed conditions, contrary to ASICs (Fig. 2B). No changes were observed for the splice variant VR5'sv (induction factor of $0.8 \pm 0.1$ ) or for VRL1 (induction factor of $0.9 \pm 0.3$ ).

If inflammatory conditions trigger a significant increase in mRNA levels for some of the ASICs, anti-inflammatory corticoids such as dexamethasone completely abolish this increase of expression for all of the increased ASICs (Fig. 2B). This increase is also suppressed by NSAIDs such as aspirin, diclofenac, and ibuprofen (Fig. 2A,B) and also salicylic acid, nimesulide, NDGA, Zileuton, or MK-886 (data not shown). None of these compounds have an effect on ASIC expression in normal animals. The action of these compounds on ASIC mRNA expression is probably attributable to the lowering of inflammatory mediators with a return to a more normal "non-inflamed" phenotype.

\section{ASIC-type currents are sensitive to NSAIDs in DRG neurons}

Under our experimental conditions, DRG neurons express three main types of $\mathrm{H}^{+}$-induced currents (Escoubas et al., 2000) as it has been described for trigeminal ganglion sensory neurons (Krishtal and Pidoplichko, 1981b). Sustained type 1 shows a small rapid transient current, followed by a sustained current that remains open as long as the acid stimulus is applied. Slowinactivating type 2 is a transient current with a slow inactivation rate. Fast-inactivating type 3 has a large transient phase with a 

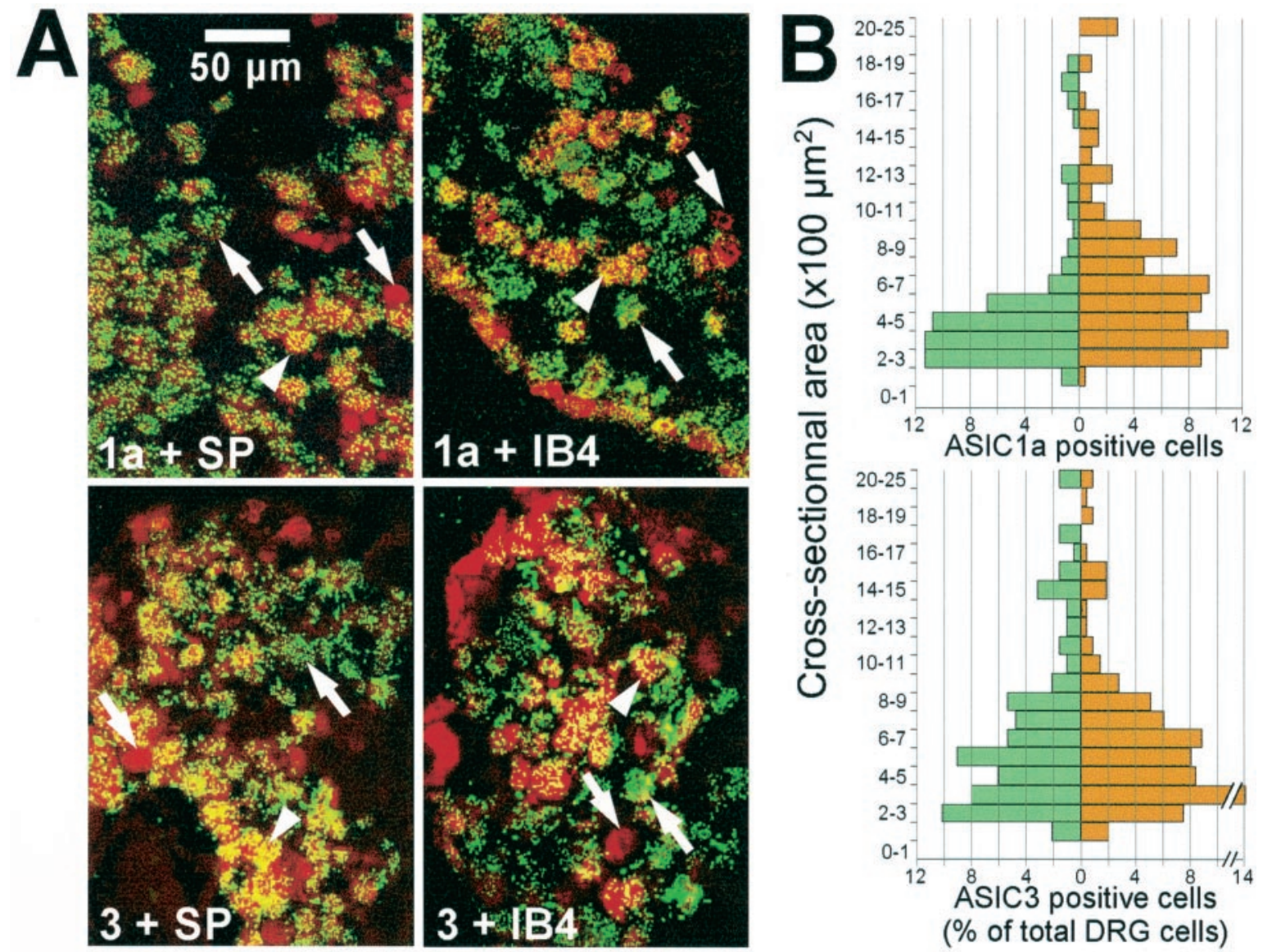

Figure 1. Expression of ASIC mRNA in DRG nociceptors in normal and inflamed conditions. A, Colocalization ( yellow) on DRG of ASIC1a or ASIC3 ( green) with SP or IB4 (red). Arrows indicate characteristic cells: arrowhead indicates a double-labeled cell; pointing-up arrow indicates an ASIC-labeled cell; and pointing-down arrow indicates an SP- or IB4-labeled cell. B, Histograms represent the ASIC1a- and ASIC3-labeled cell proportion according to cell cross-sectional areas in normal ( green) and inflamed (red) conditions. $n=3$ animals for ASIC1a (control, $n=221$ cells; inflamed, $n=210$ ), and $n=4$ animals for ASIC3 (control, $n=185$ cells; inflamed, $n=214$ ).

fast rate of inactivation, followed by a sustained phase, relatively small compared with the peak current amplitude. Salicylic acid or aspirin $(500 \mu \mathrm{M})$ inhibits the transient current of type 1 and type 2 responses and the sustained current of type 1 and type 3 responses (Fig. $3 A, B$ ), all in a reversible manner (data not shown). The fast component of type 3 response is not altered at the concentrations used. The type 2 response is reversibly inhibited by flurbiprofen (Fig. 3C), and this flurbiprofen-inhibited current is sensitive to $10 \mathrm{~nm}$ psalmotoxin-1 (PcTX1), a spider toxin that has been shown to be specific for ASIC1a (Escoubas et al., 2000) (Fig. 3C). Acetaminophen $(500 \mu \mathrm{M})$ or $200 \mu \mathrm{M}$ tolmetin, piroxicam, or etodolac have no effect on $\mathrm{H}^{+}$-gated currents.

DRG neurons also contain another type of $\mathrm{pH}$-sensitive current, the capsaicin-induced current (Bevan and Yeats, 1991). This current is sensitive to neither salicylic acid (Fig. 3D) nor flurbiprofen, aspirin, and diclofenac, at $\mathrm{pH} 7.3$ or 6.0 .

After exposure to $\mathrm{pH}$ 6, DRG neurons depolarize and trains of action potentials are generated. Aspirin $(500 \mu \mathrm{M})$ suppresses this acid-induced repetitive activity, and this inhibition is reversible (Fig. 3E). Diclofenac (200 $\mu \mathrm{M}), 500 \mu \mathrm{M}$ salicylic acid, or $500 \mu \mathrm{M}$ flurbiprofen have the same effect. This shows that $\mathrm{H}^{+}$-induced currents are able to trigger action potentials on sensory neurons and that the inhibition of these currents by NSAIDs prevents the electrical activity attributable to acidification of the extracellular medium.

\section{ASICs expressed in COS cells are directly inhibited by NSAIDs}

Because flurbiprofen selectively inhibits the PcTX1-sensitive current (Fig. $3 C$ ), we tested its inhibitory effect on ASIC1a channels expressed in COS cells (Fig. 4A,B). It blocked the channel activity with an $\mathrm{IC}_{50}$ of $349 \pm 40 \mu \mathrm{M}$ (Fig. $4 C$ ). Its analog ibuprofen has the same effect.

Aspirin $(n=9)$ or salicylic acid $(n=12)(500 \mu \mathrm{M})$ do not inhibit ASIC1a. This result suggests that the native type 2 responses in DRGs, which have kinetics of inactivation similar to ASIC1a (Waldmann and Lazdunski, 1998), can be attributable not only to homomeric ASIC1a channels (PcTX1-sensitive currents) but also to other types of isoforms compositions that lead to PcTX1-insensitive currents. Piroxicam, tolmetin, etodolac, nimesulide, or naproxen (all at $200 \mu \mathrm{M}$ ) or $500 \mu \mathrm{M}$ indomethacin have no effect on ASIC1a activity.

ASIC1b and ASIC2a are unaltered by $500 \mu \mathrm{M}$ aspirin, salicylic acid, or flurbiprofen or $200 \mu \mathrm{M}$ diclofenac (data not shown).

ASIC3 generates a biphasic current with a transient fastinactivating phase followed by a sustained phase (Waldmann et al., 1997b). Salicylic acid $\left(\mathrm{IC}_{50}\right.$ of $\left.260 \pm 21 \mu \mathrm{M}\right)$, aspirin, or diclofenac $\left(\mathrm{IC}_{50}\right.$ of $\left.92 \pm 19 \mu \mathrm{M}\right)$ inhibit the sustained current component of ASIC3 but not the transient component (Fig. $5 A-C$ ). Piroxicam, etodolac, nimesulide, naproxen (all at $200 \mu \mathrm{M}$ ) 


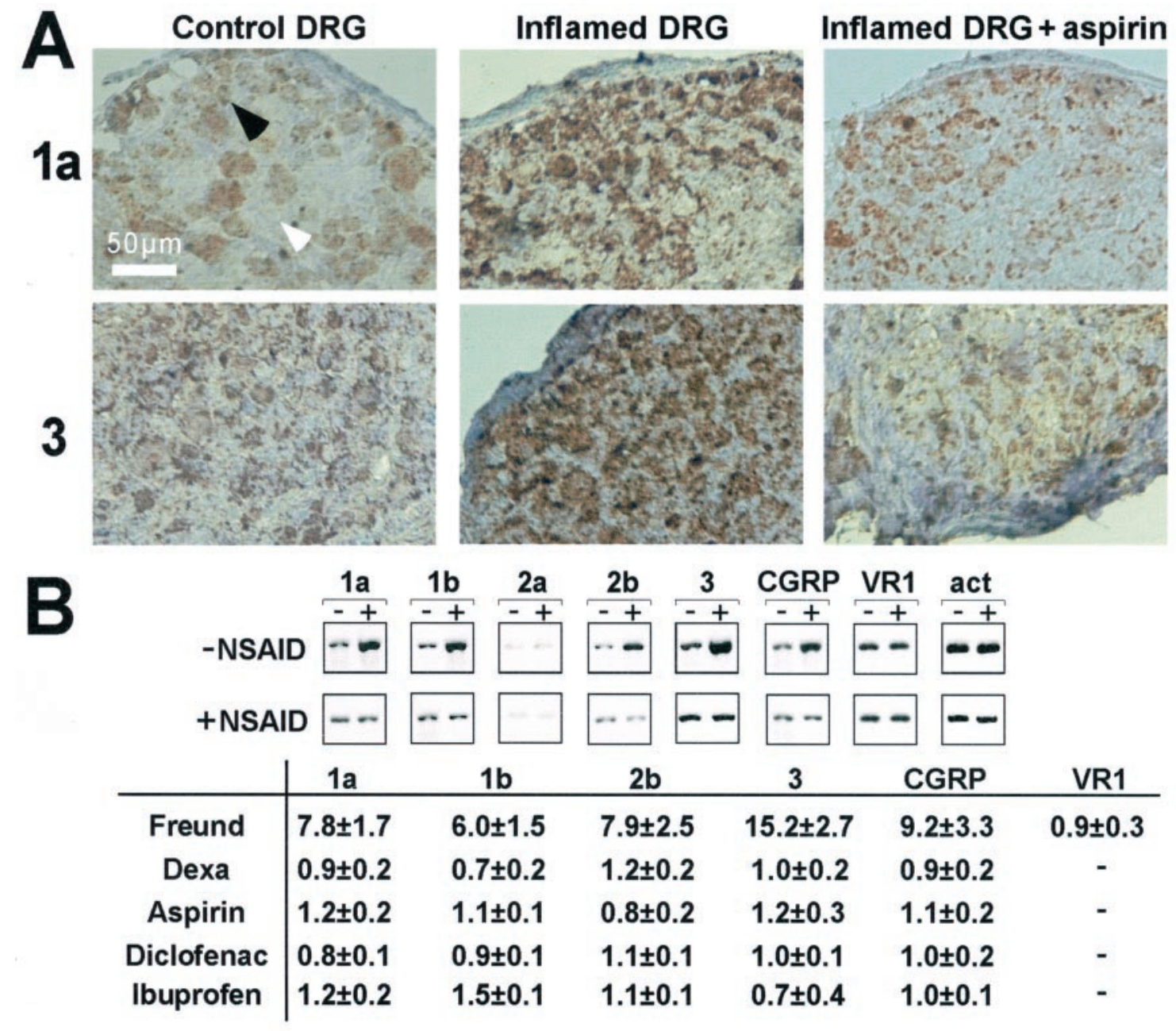

Figure 2. In vivo studies of the expression of ASIC mRNA levels in inflamed conditions and after action of NSAIDs. $A$, In situ hybridization experiments on DRG with ASIC1a and ASIC3 probes. It presents L4 DRG on the inflamed side of the animal (middle), contralateral non-inflamed DRG (left), and DRG from inflamed animal treated with aspirin (right). Arrowheads show examples of unlabeled (white) and labeled (black) cells (on 5 animals at least). $B$ shows semiquantitative RT-PCR results. Top, Representative experiments showing RT-PCR in normal $(-)$ and inflamed (+) conditions $(-$ NSAID) and after treatment with NSAID (+NSAID, here aspirin). Bottom, Induction factors (mean \pm SEM) of mRNA levels by inflammation (Freund) and after inflammation plus treatment with dexamethasone or NSAIDs ( $n=3-10$ animals per experiment). Band densities are measured and normalized to that of actin $(a c t)$ in the same preparation, and the induction factor corresponds to the ratio of the normalized densities in treated over untreated conditions.

or $500 \mu \mathrm{M}$ indomethacin or acetaminophen have no effect on ASIC3 components (data not shown).

When outside-out patches are excised from ASIC3-transfected COS cells, extracellular application of aspirin (Fig. 5D) or salicylic acid (data not shown) inhibits channel activity. This seems to indicate that the interaction of aspirin with the ASIC3 channel is direct and does not involve intracellular messengers. It is unlikely that a COX is excised along with the channel and acts as the target for the observed NSAID action on ASIC3 because COS cells do not express COX enzymes (O’Neill et al., 1994) and some NSAIDs specific for COX-1 do not inhibit the $\mathrm{pH}$-induced current.

ASIC3/ASIC2b heteromultimers (Lingueglia et al., 1997) are also inhibited by $500 \mu \mathrm{M}$ salicylic acid $(66 \pm 4 \% ; n=6)$ or $200 \mu \mathrm{M}$ diclofenac ( $49 \pm 5 \% ; n=9)$ in the same way as for ASIC3 (data not shown).

Thus, aspirin, salicylate, and diclofenac are effective on ASIC3 and ASIC2b/3 currents and none of the other NSAIDs tested are. Ibuprofen and flurbiprofen are the only active drugs against
ASIC1a currents. All of the other NSAIDs tested are without significant effect.

\section{DISCUSSION}

ASIC isoforms are present in nociceptors and are increased by inflammation

Nociceptive fibers can be divided into several groups, the largest being formed by the $\mathrm{C}$ fibers. These nociceptors have a small cell body diameter $(15-30 \mu \mathrm{m})$, unlike other sensory neurons (A $\beta$ fibers, 30-50 $\mu \mathrm{m}$; large $\mathrm{A} \alpha$ fibers, $>50 \mu \mathrm{m}$ ) (Harper and Lawson, 1985). The precise localization of ASICs in DRG neuron subtypes was still not very well known. One study had reported that ASIC1 was partially coexpressed with substance P in small DRG neurons (Olson et al., 1998) and another that ASIC1a and ASIC1b were localized in peripherin-positive and -negative neurons (Chen et al., 1998).

The present results reveal that ASIC transcripts are present in small DRG neurons i.e., nociceptors. This is in accordance with electrophysiological data showing that currents associated with 

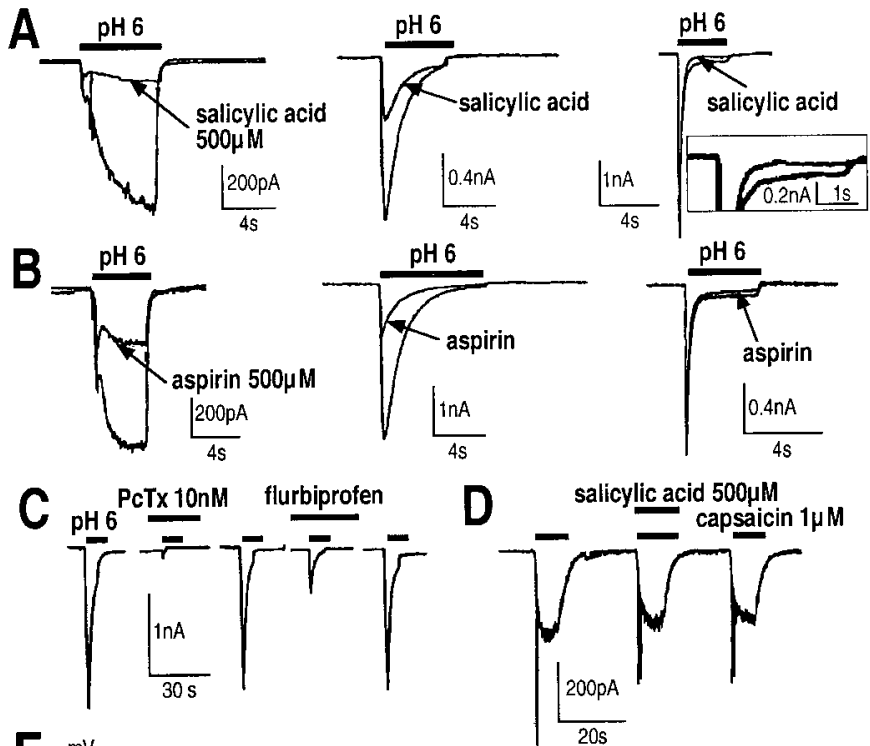

E

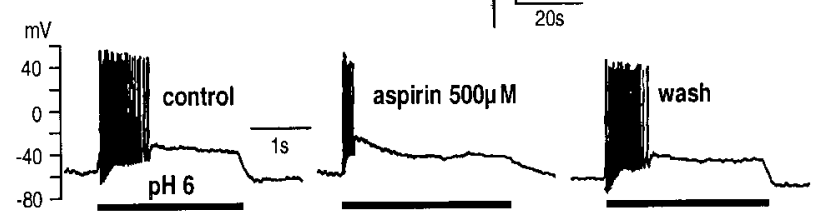

Figure 3. Action of NSAIDs on DRG cells in primary culture. Salicylic acid $(A)$ and aspirin $(B)$ inhibit $\mathrm{H}^{+}$-induced currents; inset in $A$ shows a $2.5 \times$ magnification of the inhibition. $C$, Flurbiprofen $(500 \mu \mathrm{M})$ reversibly inhibits the psalmotoxin-1-sensitive current $(n=9)$. $D$, Capsaicinactivated currents are insensitive to salicylic acid. E, Current-clamp experiments show that aspirin reduces acid-induced spiking on DRG neurons.
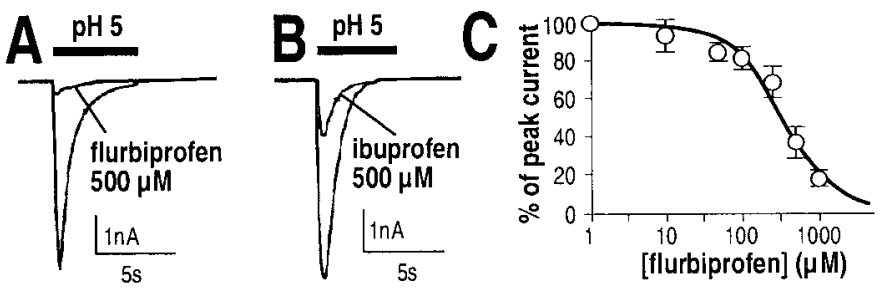

Figure 4. Action of NSAIDs on ASIC1a transfected in COS cells. Flurbiprofen $(A)$ or ibuprofen $(B)$ inhibit the current in a dose-dependent manner $(C)(5-10$ cells per data point).

$\mathrm{H}^{+}$-activated channels, and particularly ASIC1a- and ASIC3-like currents, are found in half of the small DRG neurons (Krishtal and Pidoplichko, 1981a; Bevan and Yeats, 1991), consistent with a prominent role of these channels in acid perception. These $\mathrm{H}^{+}$-induced currents are recorded in part in IB4-positive cells, as well as in SP-positive cells (Petruska et al., 2000). These $\mathrm{H}^{+}$sensitive currents, which are inhibited by amiloride, are distinct from the capsaicin-sensitive $\mathrm{H}^{+}$-induced currents because their characteristics are different and they are not present in the same population of cells (Petruska et al., 2000). The two families of channels probably have distinct roles in acid perception. One important example is ASIC3. It has been shown to be the main sensor of acid variations in the cardiac nociception system (Sutherland et al., 2001), and it is present in nociceptors that barely express a response to capsaicin.

In inflammatory conditions, the transcript levels of different ASIC isoforms are highly increased. This could signify a partic-

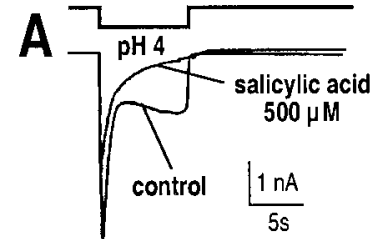

B
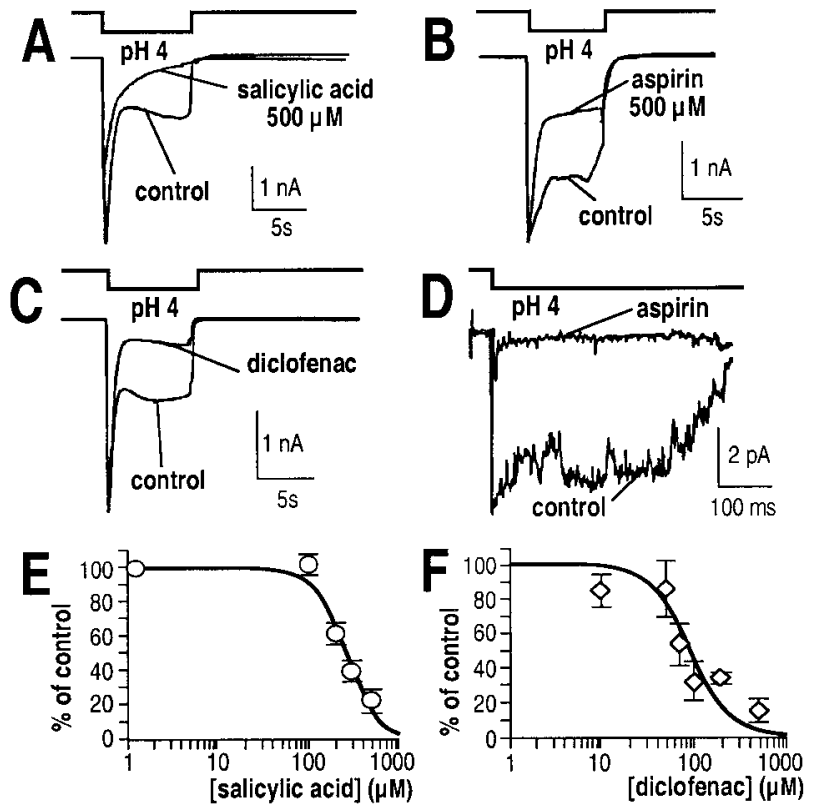

Figure 5. Action of NSAIDs on ASIC3 expressed in COS cells. Salicylic acid, aspirin, and diclofenac inhibit the current in whole-cell $(A-C)$ and outside-out $(D)$ patches. Dose dependence of the inhibition of the sustained component by salicylic acid $(E)$ or diclofenac $(F)$. Five to 10 cells per data point.

ular sensing role for these channels during inflammation. Moreover, the ASIC1a transcript appears in medium-sized cells in this condition. These newly ASIC1a-expressing cells probably could correspond to A $\beta$ fibers. This is suggested by results of Neumann et al (1996), who have shown that inflammation causes a phenotypic switch of a population of $\mathrm{A} \beta$ neurons that then acquires a pain fiber resembling phenotype by newly expressing SP (Neumann et al., 1996). This switch could participate in the hypersensitivity observed in inflammatory pain. With the appearance of ASIC1a in newly recruited neurons, an inflammatory acid stimulus can thus activate more fibers, increasing the excitability of spinal cord neurons via the release of SP.

The capsaicin (vanilloid) receptor VR1 is a cation channel expressed by primary sensory neurons. It is believed to play an important role in pain sensation (Tominaga et al., 1998; Caterina et al., 2000; Davis et al., 2000). VR1 is activated by vanilloid compounds and heat but also by protons (Caterina et al., 1997; Tominaga et al., 1998). However, the VR1 $\mathrm{H}^{+}$-induced current is different from the currents generated by ASICs and is not present in the same categories of nociceptors (Petruska et al., 2000). Mice lacking the capsaicin receptor, in which the $\mathrm{H}^{+}$-induced capsaicin-sensitive VR1 current is abolished, have an unchanged proportion of $\mathrm{H}^{+}$-induced capsaicin-insensitive current (Caterina et al., 2000; Davis et al., 2000). The capsaicin-activated current is insensitive to NSAIDs, and no difference was observed in VR1 transcript level between normal and inflamed conditions. Thus, it seems that, at least in inflammatory conditions, ASICs may have a pronounced role in acid perception. These findings are consistent with the observation that capsaicin-induced allodynia is not sensitive to ibuprofen (Kilo et al., 1995) and that capsazepine, a VR1 antagonist, does not prevent nociceptor activation induced by a combination of inflammatory mediators and low pH (Habelt et al., 2000). 


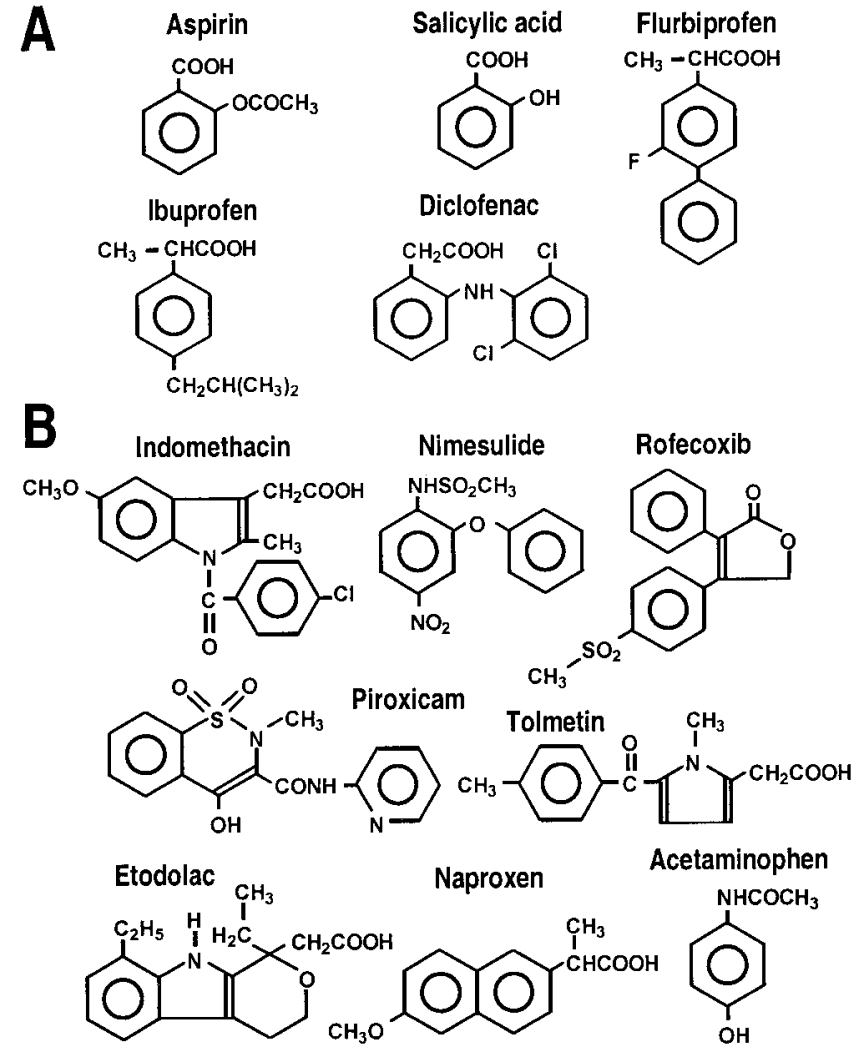

Figure 6. Chemical formulas of the NSAIDs tested on ASIC currents showing NSAIDs inhibiting ASIC activity $(A)$ and those with no action on $\operatorname{ASICs}(B)$.

\section{ASIC current subtypes in DRG neurons}

A comparison of NSAIDs action on native $\mathrm{H}^{+}$-induced currents on DRG neurons (Fig. 3) and on heterologously expressed ASICs (Figs. 4, 5) leads to new information concerning the molecular identity of native $\mathrm{H}^{+}$-induced currents. First, there are two types of slow-inactivating type 2 currents: those generated by homomeric ASIC1a channels, which are PcTX1 sensitive (Escoubas et al., 2000) and flurbiprofen sensitive (Fig. 4) and those generated by other molecular arrangements of ASIC subunits that lead to salicylate-diclofenac sensitivity. These arrangements may contain ASIC3 subunits, because ASIC3 is the only ASIC subunit to be sensitive to salicylate and diclofenac. Second, the type 3 current can be attributable to ASIC3 alone or in combination with ASIC2b (Waldmann and Lazdunski, 1998), because kinetics are similar and because, in all cases, there is a sustained phase that is sensitive to the same NSAIDs. Finally, type 1 responses could represent a more complex situation resulting from more than one current population. The type 1 response could be partly attributable to a PcTX1-insensitive type 2 current (the transient phase is inhibited by salicylate and diclofenac, like the type 2) associated with a sustained type 3-like component, because the plateau phase of the type 1 response is sensitive to the same compounds and has the same type of amplitude (several hundreds of picoamperes) as the plateau phase of type 3 .

\section{NSAID antinociception and direct inhibition of ASICs}

NSAIDs are organic acids (Fig. 6) classified according to their chemical structure: salicylic acid derivatives (aspirin and salicy- late), indole (indomethacin and etodolac) and heteroaryl (diclofenac and tolmetin) acetic acids, arylpropionic acids (ibuprofen, flurbiprofen, and naproxen), enolic acids (piroxicam), paraaminophenol derivatives (acetaminophen), and alkanones. NSAIDs show different potency against COX isoforms. Flurbiprofen, indomethacin, naproxen, and aspirin are more selective for COX-1, rofecoxib, nimesulide, and etodolac are more selective for COX-2, and ibuprofen, diclofenac, salicylate, tolmetin, and piroxicam are relatively equipotent on both $\mathrm{COX}$ isoforms (Warner et al., 1999). Acetaminophen is a weak inhibitor of COX unless it acts on another isoform (Simmons et al., 2000).

Comparing the NSAIDs that inhibit ASIC currents (Fig. 6A) with those that do not (Fig. 6B) leads to several observations. First, none of the used COX-2-specific drugs block ASIC activity, not even the highly $\mathrm{COX}-2$-selective inhibitor rofecoxib (A. Baron and M. Lazdunski, unpublished observation). Second, only some of the COX-1-specific compounds and some NSAIDs that are not COX-isoform specific act on ASIC activity. Third, the constant motif in the ASIC-inhibiting NSAIDs is a carboxylic moiety and a benzene ring. Fourth, we can predict that aspirin, which acetylates the active site of COXs (Roth et al., 1983), does not acetylate the ASICs, because their inhibition is reversible and salicylate has the same potency as aspirin.

ASICs can thus be considered as new direct targets for NSAIDs. This is not opposite to the general view of the NSAIDs mode of action involving COXs as major targets. There has been much evidence showing that NSAIDs have other targets in addition to COXs that could mediate their analgesic actions. First, COX-2-deficient mice do not present significant differences in NSAIDs-sensitive nociception compared with normal animals (Ballou et al., 2000). Second, it has been shown often that NSAIDs have analgesic effects that are independent of their action on COXs; for example $S$ - and $R$-flurbiprofen show comparable analgesic potency, although only the former inhibits COX activity (Brune et al., 1992), and diclofenac has an analgesic action that cannot be only explained by COX inhibition (Tonussi and Ferreira, 1994). In fact, a lack of correlation between the antinociceptive effects of NSAIDs and their anti-inflammatory activities has often been observed, suggesting that their analgesic properties cannot be attributable entirely to their antiinflammatory effects (McCormack and Brune, 1991; Clarke et al., 1994; McCormack, 1994), and some COX inhibitors significantly reduce pain only when administrated at a dose 100 -fold greater than necessary to inhibit COX-derived prostaglandin synthesis (Wallace, 1999).

\section{Conclusions}

One of the main conclusions of this work is that various NSAIDs are inhibitors of $\mathrm{H}^{+}$-gated channels in sensory neurons as well as cloned ASICs. The inhibition of ASICs occurs at values in the range of therapeutic doses of NSAIDs, because (1) concentrations of NSAIDs are high in inflamed areas in which they accumulate and slowly eliminate (Brune, 1977; Makela et al., 1981), (2) these compounds are often applied topically (e.g., diclofenac reaches 1-2 mM in the dermal tissue layers after skin application) (Muller et al., 1997), and (3) when given orally, high doses may be needed (e.g., aspirin and salicylate are often prescribed to reach 1-3 mm plasma concentrations) (Famaey and Paulus, 1992). Our results can also explain why topical applications of commercial solutions of NSAIDs (such as aspirin and ibuprofen) are able to relieve cutaneous pain induced by infusions of acidic solutions in humans (Steen et al., 1996). In addition to their direct effect on 
$\mathrm{H}^{+}$-gated channels, NSAIDs block inflammation and hence the large inflammation-induced increase of ASIC transcription. We propose that the two effects, i.e., direct channel block and inhibition of inflammation-induced ASIC expression, play an important role in the antinociceptive effects of NSAIDs in addition to their well known effects on COXs and more particularly in case of inflammation. These observations could lead to new therapeutic openings to treat pain.

\section{REFERENCES}

Amara SG, Arriza JL, Leff SE, Swanson LW, Evans RM, Rosenfeld MG (1985) Expression in brain of a messenger RNA encoding a novel neuropeptide homologous to calcitonin gene-related peptide. Science 229:1094-1097.

Ballou LR, Botting RM, Goorha S, Zhang J, Vane JR (2000) Nociception in cyclooxygenase isozyme-deficient mice. Proc Natl Acad Sci USA 97:10272-10276.

Bevan S, Yeats J (1991) Protons activate a cation conductance in a sub-population of rat dorsal root ganglion neurons. J Physiol (Lond) 433:145-161.

Brune K (1977) Biodistribution of salicylates: a clue to the understanding of some effects and side effects. Agents Actions Suppl 2:163-177.

Brune K, Menzel-Soglowek S, Zeilhofer HU (1992) Differential analgesic effects of aspirin-like drugs. Drugs 44 [Suppl 5]:52-59.

Caterina MJ, Schumacher MA, Tominaga M, Rosen TA, Levine JD, Julius D (1997) The capsaicin receptor: a heat-activated ion channel in the pain pathway. Nature 389:816-824.

Caterina MJ, Rosen TA, Tominaga M, Brake AJ, Julius D (1999) A capsaicin-receptor homologue with a high threshold for noxious heat. Nature 398:436-441.

Caterina MJ, Leffler A, Malmberg AB, Martin WJ, Trafton J, PetersenZeitz KR, Koltzenburg M, Basbaum AI, Julius D (2000) Impaired nociception and pain sensation in mice lacking the capsaicin receptor. Science 288:306-313.

Chen CC, England S, Akopian AN, Wood JN (1998) A sensory neuronspecific, proton-gated ion channel. Proc Natl Acad Sci USA 95:10240-10245.

Chen X, Gallar J, Belmonte C (1997) Reduction by antiinflammatory drugs of the response of corneal sensory nerve fibers to chemical irritation. Invest Ophthalmol Vis Sci 38:1944-1953.

Clarke GD, MacPherson IS, Petrone G, Spangler RS (1994) Antinociceptive effects of non-steroidal anti-inflammatory drugs in a rat model of unilateral hindpaw inflammation. Eur $\mathrm{J}$ Pharmacol 257:103-108.

Davis JB, Gray J, Gunthorpe MJ, Hatcher JP, Davey PT, Overend P, Harries MH, Latcham J, Clapham C, Atkinson K, Hughes SA, Rance K, Grau E, Harper AJ, Pugh PL, Rogers DC, Bingham S, Randall A, Sheardown SA (2000) Vanilloid receptor-1 is essential for inflammatory thermal hyperalgesia. Nature 405:183-187.

Donaldson LF, Harmar AJ, McQueen DS, Seckl JR (1992) Increased expression of preprotachykinin, calcitonin gene-related peptide, but not vasoactive intestinal peptide messenger RNA in dorsal root ganglia during the development of adjuvant monoarthritis in the rat. Brain Res Mol Brain Res 16:143-149.

Escoubas P, De Weille JR, Lecoq A, Diochot S, Waldmann R, Champigny G, Moinier D, Menez A, Lazdunski M (2000) Isolation of a tarantula toxin specific for a class of proton-gated $\mathrm{Na}^{+}$channels. J Biol Chem 275:25116-25121.

Famaey JP, Paulus HE (1992) Therapeutic applications of NSAIDs: subpopulations and new formulations, Vol 10. New York: Dekker.

Garcia-Añoveros J, Samad TA, Zuvela-Jelaska L, Woolf CJ, Corey DP (2001) Transport and localization of the $\mathrm{DEG} / \mathrm{ENaC}$ ion channel $\mathrm{BNaC} 1 \alpha$ to peripheral mechanosensory terminals of dorsal root ganglia neurons. J Neurosci 21:2678-2686.

Habelt C, Kessler F, Distler C, Kress M, Reeh PW (2000) Interactions of inflammatory mediators and low $\mathrm{pH}$ not influenced by capsazepine in rat cutaneous nociceptors. NeuroReport 11:973-976.

Harper AA, Lawson SN (1985) Conduction velocity is related to morphological cell type in rat dorsal root ganglion neurons. J Physiol (Lond) 359:31-46.

Helmlinger G, Yuan F, Dellian M, Jain RK (1997) Interstitial pH and pO2 gradients in solid tumors in vivo: high-resolution measurements reveal a lack of correlation. Nat Med 3:177-182.

Kilo S, Forster C, Geisslinger G, Brune K, Handwerker HO (1995) Inflammatory models of cutaneous hyperalgesia are sensitive to effects of ibuprofen in man. Pain 62:187-193.
Kress M, Zeilhofer HU (1999) Capsaicin, protons and heat: new excitement about nociceptors. Trends Pharmacol Sci 20:112-118.

Krishtal OA, Pidoplichko VI (1981a) A receptor for protons in the membrane of sensory neurons may participate in nociception. Neuroscience 6:2599-2601.

Krishtal OA, Pidoplichko VI (1981b) A "receptor" for protons in small neurons of trigeminal ganglia: possible role in nociception. Neurosci Lett 24:243-246.

Lingueglia E, de Weille JR, Bassilana F, Heurteaux C, Sakai H, Waldmann R, Lazdunski M (1997) A modulatory subunit of acid sensing ion channels in brain and dorsal root ganglion cells. J Biol Chem 272:29778-29783.

Makela AL, Lempiainen M, Ylijoki H (1981) Ibuprofen levels in serum and synovial fluid. Scand J Rheumatol Suppl 39:15-17.

McCormack K (1994) The spinal actions of nonsteroidal antiinflammatory drugs and the dissociation between their antiinflammatory and analgesic effects. Drugs 5:28-45.

McCormack K, Brune K (1991) Dissociation between the antinociceptive and anti-inflammatory effects of the nonsteroidal antiinflammatory drugs. A survey of their analgesic efficacy. Drugs 41:533-547.

Muller M, Mascher H, Kikuta C, Schafer S, Brunner M, Dorner G, Eichler HG (1997) Diclofenac concentrations in defined tissue layers after topical administration. Clin Pharmacol Ther 62:293-299.

Neumann S, Doubell TP, Leslie T, Woolf CJ (1996) Inflammatory pain hypersensitivity mediated by phenotypic switch in myelinated primary sensory neurons. Nature 384:360-364.

Nudel U, Zakut R, Shani M, Neuman S, Levy Z, Yaffe D (1983) The nucleotide sequence of the rat cytoplasmic beta-actin gene. Nucleic Acids Res 11:1759-1771.

O’Neill GP, Mancini JA, Kargman S, Yergey J, Kwan MY, Falgueyret JP, Abramovitz M, Kennedy BP, Ouellet M, Cromlish W, Culp S, Evans JF, Ford-Hutchinson AW, Vickers PJ (1994) Overexpression of human prostaglandin $\mathrm{G} / \mathrm{H}$ synthase- 1 and -2 by recombinant vaccinia virus: inhibition by nonsteroidal anti-inflammatory drugs and biosynthesis of 15-hydroxyeicosatetraenoic acid. Mol Pharmacol 45:245-254.

Olson TH, Riedl MS, Vulchanova L, Ortiz-Gonzalez XR, Elde R (1998) An acid sensing ion channel (ASIC) localizes to small primary afferent neurons in rats. NeuroReport 9:1109-1113.

Petruska JC, Napaporn J, Johnson RD, Gu JG, Cooper BY (2000) Subclassified acutely dissociated cells of rat DRG: histochemistry and patterns of capsaicin-, proton-, and ATP-activated currents. J Neurophysiol 84:2365-2379.

Reeh PW, Steen KH (1996) Tissue acidosis in nociception and pain. Prog Brain Res 113:143-151.

Roth GJ, Machuga ET, Ozols J (1983) Isolation and covalent structure of the aspirin-modified, active-site region of prostaglandin synthetase. Biochemistry 22:4672-4675.

Schumacher MA, Moff I, Sudanagunta SP, Levine JD (2000) Molecular cloning of an N-terminal splice variant of the capsaicin receptor. Loss of $\mathrm{N}$ terminal domain suggests functional divergence among capsaicin receptor subtypes. J Biol Chem 275:2756-2762.

Simmons DL, Wagner D, Westover K (2000) Nonsteroidal antiinflammatory drugs, acetaminophen, cyclooxygenase 2 , and fever. Clin Infect Dis 31:S211-S218.

Snider WD, McMahon SB (1998) Tackling pain at the source: new ideas about nociceptors. Neuron 20:629-632.

Steen KH, Reeh PW (1993) Sustained graded pain and hyperalgesia from harmless experimental tissue acidosis in human skin. Neurosci Lett 154:113-116.

Steen KH, Steen AE, Reeh PW (1995) A dominant role of acid pH in inflammatory excitation and sensitization of nociceptors in rat skin, in vitro. J Neurosci 15:3982-3989.

Steen KH, Reeh PW, Kreysel HW (1996) Dose-dependent competitive block by topical acetylsalicylic and salicylic acid of low $\mathrm{pH}$-induced cutaneous pain. Pain 64:71-82.

Stein C, Millan MJ, Herz A (1988) Unilateral inflammation of the hindpaw in rats as a model of prolonged noxious stimulation: alterations in behavior and nociceptive thresholds. Pharmacol Biochem Behav 31:455-461.

Sutherland SP, Benson CJ, Adelman JP, McCleskey EW (2001) Acidsensing ion channel 3 matches the acid-gated current in cardiac ischemia-sensing neurons. Proc Natl Acad Sci USA 98:711-716.

Tominaga M, Caterina MJ, Malmberg AB, Rosen TA, Gilbert H, Skinner K, Raumann BE, Basbaum AI, Julius D (1998) The cloned capsaicin receptor integrates multiple pain-producing stimuli. Neuron 21:531-543.

Tonussi CR, Ferreira SH (1994) Mechanism of diclofenac analgesia: direct blockade of inflammatory sensitization. Eur $\mathrm{J}$ Pharmacol 251:173-179. 
Vane JR, Botting RM (1998) Mechanism of action of antiinflammatory drugs. Int J Tissue React 20:3-15.

Waldmann R, Lazdunski M (1998) H(+)-gated cation channels: neuronal acid sensors in the $\mathrm{NaC} / \mathrm{DEG}$ family of ion channels. Curr Opin Neurobiol 8:418-424.

Waldmann R, Champigny G, Voilley N, Lauritzen I, Lazdunski M (1996) The mammalian degenerin MDEG, an amiloride-sensitive cation channel activated by mutations causing neurodegeneration in Caenorhabditis elegans. J Biol Chem 271:10433-10436.

Waldmann R, Champigny G, Bassilana F, Heurteaux C, Lazdunski M (1997a) A proton-gated cation channel involved in acid-sensing. Nature 386:173-177.
Waldmann R, Bassilana F, de Weille J, Champigny G, Heurteaux C, Lazdunski M (1997b) Molecular cloning of a non-inactivating protongated $\mathrm{Na}^{+}$channel specific for sensory neurons. J Biol Chem 272:20975-20978.

Walker JS (1995) NSAID: an update on their analgesic effects. Clin Exp Pharmacol Physiol 22:855-860.

Wallace JL (1999) Selective COX-2 inhibitors: is the water becoming muddy? Trends Pharmacol Sci 20:4-6.

Warner TD, Giuliano F, Vojnovic I, Bukasa A, Mitchell JA, Vane JR (1999) Nonsteroid drug selectivities for cyclo-oxygenase-1 rather than cyclo-oxygenase-2 are associated with human gastrointestinal toxicity: a full in vitro analysis. Proc Natl Acad Sci USA 96:7563-7568. 